\title{
Application of a targeted and quantificational foraminoplasty device in percutaneous transforaminal endoscopic discectomy for L5-S1 disc herniation: preliminary clinical outcomes
}

\author{
Jinlong Liu ${ }^{1 \dagger}$, Junlong $\mathrm{Wu}^{2,3+}$, Honglei Zhang ${ }^{1}$, Rui Zuo ${ }^{4}$, Jiabin Liu ${ }^{4}$ and Chao Zhang ${ }^{4^{*}}$ (i)
}

\begin{abstract}
Objective: Percutaneous transforaminal endoscopic discectomy (PTED) is minimally invasive and has been widely used to treat patients with lumbar disc herniation $(\mathrm{LDH})$ due to its safety and efficiency. However, due to the unique anatomy of the L5-S1 level, the PTED procedure is often difficult to perform in the region. ZESSYS, a targeted and quantificational foraminoplasty device, may help to overcome these anatomical limitations. In this study, we assessed the efficiency and the short-term effects of PTED with ZESSYS at the L5-S1 level.

Methods: Between January and August of 2018, fifty-six patients with lumbar disc herniation at the single level of L5-S1 and who underwent percutaneous transforaminal endoscopic discectomy were enrolled in this retrospective cohort study. They were segregated into the transforaminal endoscopic surgical system (TESSYS) group and the ZESSYS group. The puncture time, foraminoplasty time, decompression time, and fluoroscopy time were evaluated for operation efficiency. Clinical outcomes were assessed by the visual analog scale (VAS) score and Oswestry Disability Index (ODI) score. The MacNab criteria were used to evaluate patient subjective satisfaction at 12-month follow-up postoperatively.

Results: The average puncture time (5.29 $\pm 2.05 \mathrm{~min})$, foraminoplasty time (12.82 $\pm 2.52 \mathrm{~min})$, and fluoroscopy time $(26.29 \pm 5.96 \mathrm{~s})$ were all significantly shorter in the ZESSYS group than in the TESSYS group (average puncture time $8.07 \pm 3.13 \mathrm{~min}, p<0.01$; foraminoplasty time, $17.18 \pm 2.92 \mathrm{~min}, p<0.01$; fluoroscopy time, $34.73 \pm 6.86 \mathrm{~s} ; p<0.01$ ). No significant differences were observed between the 2 groups in the decompression time $(p=0.057)$. The VAS score of low back pain and leg pain, as well as the ODI score, improved at all time points postoperatively compared with preoperative, in both the TESSYS group and the ZESSYS group $(P<0.05)$. There were no significant differences in the VAS score of low back pain, VAS score of leg pain, and ODI score between the TESSYS group and the ZESSYS group at the same time points $(P>0.05)$. According to the MacNab criteria, the excellent and good rate at 12 -month follow-up postoperatively was $85.7 \%$ in the TESSYS group and $89.3 \%$ in the ZESSYS group $(P>0.05)$.
\end{abstract}

\footnotetext{
* Correspondence: czspine11@163.com

† Jinlong Liu and Junlong Wu contributed equally to this work.

${ }^{4}$ Department of Spine Surgery, Xinqiao Hospital, Army Medical University, Chongqing 400037, China

Full list of author information is available at the end of the article
}

(c) The Author(s). 2021 Open Access This article is licensed under a Creative Commons Attribution 4.0 International License, which permits use, sharing, adaptation, distribution and reproduction in any medium or format, as long as you give appropriate credit to the original author(s) and the source, provide a link to the Creative Commons licence, and indicate if changes were made. The images or other third party material in this article are included in the article's Creative Commons licence, unless indicated otherwise in a credit line to the material. If material is not included in the article's Creative Commons licence and your intended use is not permitted by statutory regulation or exceeds the permitted use, you will need to obtain permission directly from the copyright holder. To view a copy of this licence, visit http://creativecommons.org/licenses/by/4.0/ The Creative Commons Public Domain Dedication waiver (http://creativecommons.org/publicdomain/zero/1.0/) applies to the data made available in this article, unless otherwise stated in a credit line to the data. 
Conclusion: The targeted and quantificational foraminoplasty device named ZESSYS was more efficient in the puncture and foraminoplasty procedures, effectively protecting the exiting nerve and minimizing the level of radiation exposure. The device is efficient and safe for PTED in treating lumbar disc herniation at the L5-S1 level.

Keywords: Percutaneous transforaminal endoscopic discectomy, Lumbar disc herniation at the L5-S1 level, Foraminoplasty, Preliminary clinical outcomes

\section{Introduction}

Lumbar disc herniation (LDH) is a frequently occurring disease of the spine and leads to economic and medical burdens on families and society $[1,2]$. Conservative treatment for LDH is effective, but a considerable number of patients will ultimately receive surgical treatment $[3,4]$. Open microdiscectomy has been considered as the standard for surgical treatment for LDH until now. However, in recent decades, percutaneous transforaminal endoscopic discectomy (PTED), via a posterolateral approach, has gained popularity in clinical practice due to advantages such as little trauma, few scar, a rapid recovery, and a short hospital stay [5-9]. For this minimally invasive surgery, a working cannula with a diameter of $7.5 \mathrm{~mm}$ needs to be introduced safely to the space in front of the spinal dural sac via the posterolateral direction, and foraminoplasty often needs to be performed to enlarge the intervertebral foramen. The superior articular process (SAP) is the main obstacle for foraminoplasty. Transforaminal endoscopic surgical system (TESS YS) is a classic technique that was invented by Hoogland et al. [10] in 2006. Graded isocentric trephine and accompanying instruments are used to cut the upper and ventral aspects of the SAP. The intervertebral foramen is widened gradually so that the working cannula and rodshaped endoscope can enter the epidural space. Extruded and sequestered discs can be resected and the region of foraminal stenosis can be decompressed directly. However, in this procedure, the isocentric trephine makes contact with the exiting nerve root, traversing the nerve root and para-foramen soft tissue, which is risk and arising concerns of damage to nerves [11]. In addition, at the L5-S1 level, the unique anatomy involving a high iliac crest, sacral ala, large facet joint, large L5 transverse process, narrowed disc space, and narrowed foramen can complicate the foraminoplasty process. These anatomical obstacles and inter-individual variability in the anatomy make PTED technically challenging [12]. PTED is more difficult to perform at this level in particular [13], even for skilled and experienced surgeons.

ZESSYS is a novel targeted and quantificational foraminoplasty device that originated from a modified version of the traditional TESSYS technique. The novel effective foraminoplasty tool was designed by Yue Zhou et al. from the Second Affiliated Xinqiao Hospital of
Army Medical University in Chongqing, China. The hypothesis is that it would be easier to implement and may help overcome the anatomical limitations at the L5-S1 level. In this study, the novel targeted and quantificational foraminoplasty device was used to perform PTED at the L5-S1 level. Meanwhile, its foraminoplasty efficiency and the short-term clinical outcomes were assessed.

\section{Materials and methods \\ Patients}

From January to August of 2018, a total of fifty-six patients with lumbar disc herniation who were treated in the Department of Orthopedics in Xinqiao Hospital at the Army Medical University were enrolled in the study. The inclusion criteria were as follows: (1) lumbar disc herniation at the single level of L5-S1 confirmed by preoperative magnetic resonance imaging (MRI) and computed tomography (CT) scans; (2) low back pain accompanied by sciatica and corresponding radiculopathy signs such as motor weakness, sensory deficiency, and the presence of abnormal reflex (more than one of the above signs); (3) a lack of improvement after conservative treatment for at least 12 weeks; and (4) an age of 18-70 years. The exclusion criteria were as follows: (1) central stenosis (less than $10 \mathrm{~mm}$ ) or lateral recess stenosis (less than $3 \mathrm{~mm}$ ) confirmed by MRI and CT scans, (2) spinal instability confirmed by dynamic radiographs, (3) calcified disc herniation, (4) far lateral disc herniation, (5) a history of surgery in the same segment, (6) cauda equina syndrome, (7) BMI $>28 \mathrm{~kg} / \mathrm{m}^{2}$, and (8) the unwillingness or inability to participate in the treatment. All 56 patients were averaged to the TESSYS and the ZESSYS group. All the patients completed the follow-up at 12 months postoperatively. All the study procedures were approved by the Ethics Committee of Xinqiao Hospital, at the Army Medical University. The procedures were performed by a single skilled and experienced surgeon.

\section{Surgical methods \\ Surgical instruments}

The spine transforaminal endoscope system (TESSYS instrument system: Joimax, Inc., Irvine, CA, USA) and tip-flexible electrode bipolar radiofrequency system (Elliquence LLC, Baldwin, New York, USA) were used in 
the two groups. In the ZESSYS group, the patented ZESSYS instrument instead of the conventional grade guide rod and trephine was used for targeted and quantificational foraminoplasty. ZESSYS is a dual-cannula instrument that has 4 graded sizes. The thinner cannula contains Kirschner wire for fixation and the other larger cannula for foraminoplasty by using a trephine. The detailed characteristics of ZESSYS including the external form, initial application, and advantages were first detailed by Ao et al. [14]. C-arm fluoroscopy was used for radiograph imaging in both groups.

\section{Surgical procedures}

TESSYS The procedure was performed with local anesthesia combined with analgesic drugs. The patient laid on the radiolucent table in the prone position, and a soft and frame cushion was placed beneath the abdomen to reduce the degree of lumbar lordosis and avoid abdominal compression. The puncture point was 12-14 $\mathrm{cm}$ from the middle line and a short distance from the iliac crest if the iliac crest obstacle to the predetermined trajectory. Local infiltration anesthesia was induced by $0.5 \%$ lidocaine around the puncture point. An 18-gauge needle was inserted toward the upper and ventral surface of the SAP for stepwise and additional local anesthesia. After the cranial part of the SAP was crossed, the tip of the 18-gauge needle was pushed gently to the ideal epidural position toward the middle line of the vertebral canal under anteroposterior imaging and toward the vertebral posterior superior margin under lateral imaging to the greatest extent possible. If needed, an adjustment toward the herniated disc was performed. At that point, the 18-gauge needle was withdrawn and replaced by a guidewire. Over the guidewire, a stab incision measuring approximately $1 \mathrm{~cm}$ was made, and stepwise guiding and dilatation rods were introduced. Subsequently, foraminoplasty was performed after the ventral side of SAP was partially removed with the expansion tube, guide rod, and trephine in sequence. After surgical access was established, a working channel slope was placed close to the intervertebral disc. In all cases, the herniated disc and the extruding or sequestrated disc fragment could be observed. Then, discectomy and nerve root decompression were performed in the same manner as was the routine PTED procedure. After decompression, the surgical instruments were pulled out, and the wound was sutured.

ZESSYS This procedure was also performed with local anesthesia combined with analgesic drugs. The protocol used before the puncture step was identical to that used in the TESSYS group. An 18-gauge needle was inserted into the foramen and across the safe triangle stepwise.
During this step, the needle was inserted along the ventral aspect of the SAP to prevent exiting nerve root injury. The needle was then replaced by a $1-\mathrm{mm}$ guidewire with a stab incision measuring approximately $1 \mathrm{~cm}$. After traditional graded dilation, the $1-\mathrm{mm}$ guidewire and the smallest guide rod were replaced by a $2.5-\mathrm{mm}$ Kirschner wire which was slightly hammered across the safe triangle and fixed on the superior-lateral part of the posterior aspect of the distal vertebra. Based on the location of the Kirschner wire tip on the anteroposterior and lateral view, the extent of deviation to the target point was assessed and the double-cannula device with a properly predetermined size was selected. As a rule, selection of larger size can provide more ventral bony ablation of the SAP and will obtain final intracanal positioning that is closer to the middle line on the anteroposterior view. Following the Kirschner wire, the suitable doublecannula device was inserted until the larger cannula reached the SAP through the incision. Afterwards, the double-cannula device was rotated and centered on the Kirschner wire to determine the ideal starting point and trajectory to the target point on the anteroposterior and lateral view. Foraminoplasty was then performed by a trephine, and part of the ventral side of the SAP was cut and removed. If needed, the foramen was widened further by a larger graded cannula or another rotational motion. Then, discectomy and nerve root decompression were performed in the same manner as in the routine PTED procedure. After decompression, the surgical instruments were pulled out, and the wound was sutured.

\section{Statistical analysis}

Statistical analyses were performed using the SPSS 17.0 statistical package (SPSS, Inc., Chicago, IL, USA). The two independent samples t-test, paired t-test, chi-square test, and Mann-Whitney $U$ test were used for data analyses. The measurement data are presented as the means \pm standard deviations. For all analyses, a p value less than 0.05 was considered statistically significant.

\section{Results \\ Patient demographic data}

Fifty-six patients (TESSYS, 28 patients; ZESSYS, 28 patients) who underwent PTED surgery from January to August of 2018 were enrolled in this study. The baseline demographics for both groups are shown in Table 1. The grade of foraminal stenosis on the operative side at L5-S1 was classified according to the report of Lee et al. [15]. The grade of iliac height at L5-S1 was classified according to the report of Choi et al. [16]. No significant differences were observed between the 2 groups (Table 1). 
Table 1 Patient demographic data for the TESSYS and ZESSYS groups

\begin{tabular}{llll}
\hline & TESSYS & ZESSYS & $\boldsymbol{p}$ value \\
\hline Age, years & $52.54 \pm 9.10$ & $49.21 \pm 10.38$ & 0.208 \\
Sex, male:female & $18: 10$ & $15: 13$ & 0.415 \\
ASA criteria, I:Il & $20: 8$ & $18: 10$ & 0.571 \\
BMI $\left(\mathrm{kg} / \mathrm{m}^{2}\right)$ & $22.28 \pm 2.69$ & $21.99 \pm 2.22$ & 0.659 \\
Smoker, yes:no & $16: 12$ & $17: 11$ & 0.786 \\
Duration of symptoms, weeks & $15.21 \pm 2.54$ & $16.04 \pm 2.96$ & 0.271 \\
Herniation type, contained:uncontained & $9: 19$ & $11: 17$ & 0.577 \\
Foraminal stenosis grade (L5-S1) 0:1:2:3 & $19: 9: 0: 0$ & $17: 10: 1: 0$ & 0.523 \\
Iliac height grade & $0: 0: 3: 8: 10: 7$ & $0: 0: 1: 9: 11: 7$ & 0.730 \\
1:2:3:4:5:6 & & &
\end{tabular}

ASA American Society of Anesthesiologists, $B M I$ body mass index

\section{Clinical outcomes}

As shown in Table 2, the average puncture time (5.29 $\pm 2.05 \mathrm{~min})$, foraminoplasty time $(12.82 \pm 2.52 \mathrm{~min})$, fluoroscopy time $(26.29 \pm 5.96 \mathrm{~s})$, and total surgery time $(63.14 \pm 7.76 \mathrm{~min})$ in the ZESSYS group were significantly shorter than those in the TESSYS group (average puncture time $8.07 \pm 3.13 \mathrm{~min}, p<0.01$; foraminoplasty time, $17.18 \pm 2.92 \mathrm{~min}, p<0.01$; fluoroscopy time, $34.73 \pm 6.86 \mathrm{~s} ; p<0.01$; total surgery time $74.21 \pm 12.16 \mathrm{~min}, p<0.01)$. No significant differences were observed between the 2 groups in the decompression time $(p=0.057)$.

As shown in Table 3, the VAS scores for low back pain and leg pain, as well as the ODI score, improved at all time points postoperatively, both in the TESSYS group and the ZESSYS group $(p<0.05)$. There were no significant differences in the VAS score for low back pain, VAS score for leg pain, ODI score, or MacNab criteria between the TESSYS group and the ZESSYS group at the same time points $(p>0.05)$. The excellent and good rate according to the MacNab criteria at 12 months postoperatively was $85.7 \%$ in the TESSYS group and 89.3\% in the ZESSYS group.

\section{Operation complications}

All the patients in the two groups were successfully decompressed with immediate nerve relief. No cases required conversion to an open procedure, and no major

Table 2 Comparison of the intraoperative outcomes between the TESSYS and ZESSYS groups

\begin{tabular}{llll}
\hline & TESSYS & ZESSYS & $\boldsymbol{p}$ value \\
\hline Puncture time (min) & $8.07 \pm 3.13$ & $5.29 \pm 2.05$ & $<0.01$ \\
Foraminoplasty time (min) & $17.18 \pm 2.92$ & $12.82 \pm 2.52$ & $<0.01$ \\
Fluoroscopy time (s) & $34.73 \pm 6.86$ & $26.29 \pm 5.96$ & $<0.01$ \\
Decompression time (min) & $48.96 \pm 9.02$ & $45.04 \pm 5.65$ & 0.057 \\
Total surgery time (min) & $74.21 \pm 12.16$ & $63.14 \pm 7.76$ & $<0.01$ \\
\hline
\end{tabular}

complications such as dural tears, infections, or vascular injuries were observed. One patient in the TESSYS group developed postoperative dysesthesia (POD), which was considered to be caused by irritation to the dorsal root ganglion. With temporary conservative treatment, the symptoms disappeared. No cases of recurrent herniation were observed at the 12-month follow-up.

\section{Discussion}

PTED technic has been an effective and safe procedure for LDH [17-20]. Hoogland et al. firstly invented the TESSYS technique, in which a graded trephine was used

Table 3 Comparison of the clinical outcomes of the TESSYS and ZESSYS groups

\begin{tabular}{llll}
\hline & \multicolumn{1}{l}{ TESSYS } & \multicolumn{1}{l}{ ZESSYS } & $\boldsymbol{p}$ value \\
\hline VAS score for low back pain & & \\
Preoperative & $3.60 \pm 0.95$ & $3.38 \pm 0.69$ & 0.310 \\
Postoperative & $2.20 \pm 0.92^{*}$ & $2.36 \pm 1.03^{*}$ & 0.541 \\
12 months & $1.48 \pm 1.02^{*}$ & $1.30 \pm 0.84^{*}$ & 0.467 \\
VAS score for leg pain & & & \\
Preoperative & $5.91 \pm 1.23$ & $6.17 \pm 1.61$ & 0.505 \\
Postoperative & $2.10 \pm 0.97^{*}$ & $2.25 \pm 0.86^{*}$ & 0.532 \\
12 months & $1.22 \pm 0.70^{*}$ & $1.10 \pm 0.84^{*}$ & 0.572 \\
ODI score & & & \\
Preoperative & $59.36 \pm 8.33$ & $61.57 \pm 7.89$ & 0.312 \\
Postoperative & $15.50 \pm 4.48^{*}$ & $16.07 \pm 4.82^{*}$ & 0.648 \\
12 months & $12.50 \pm 3.06^{*}$ & $12.07 \pm 3.67^{*}$ & 0.637 \\
MacNab criteria (12 months) & & \\
Excellent & 17 & 19 & \\
Good & 7 & 6 & \\
Fair & 4 & 3 & \\
Poor & 0 & 0 & \\
\hline $\begin{array}{l}\text { VAS visual analog scale, ODI Oswestry Disability lndex } \\
\text { Compared with preoperatively, } P<0.05\end{array}$ & &
\end{tabular}


to enlarge the foramen gradually and the working channel slope was placed close to the intervertebral disc. However, the extruded and sequestered disc fragments are accessible only when the operating instruments are placed in the optimal trajectory. Accuracy was highly demanded, especially for the puncture and foraminoplasty procedure. At the L5-S1 level, the high iliac crest is a major block for the PTED procedure. The high iliac crest in some cases limited the ideal angle of puncture and channel implantation. Failure of puncture was reported in many cases. The other anatomy includes sacral ala, large L5 transverse process, large facet joint, narrowed disc space, and narrow foramen which also complicate the puncture [21], foraminoplasty, and channel indwelling processes of PTED. The unique anatomy at the L5-S1 level leads to a steeper learning curve [22] and challenges, even for skilled surgeons. In addition, the gradual trephine is isocentric, which increases the risk of damage to nerve roots. Most POD cases due to dorsal root ganglia stimulation or injury have been reported to occur in L5-S1 during the PTED procedure $[23,24]$. Therefore, the interlaminar approach and transiliac approach endoscopic surgery were used to treat $\mathrm{LDH}$ at the L5-S1 level. But these two techniques had defects. It was hard to resect lateral and far lateral herniated nucleus pulposus through the interlaminar approach. The transiliac approach would cause additional damage to the iliac and had a potential risk of the sacroiliac joint and peripheral soft tissue injury. In addition, the accurate puncture point of the iliac and safety working channel were difficult to position. To address the above problem, the ZESSYS, a targeted and quantificational foraminoplasty device with a double cannula, is conducive to overcoming the anatomic limitations at the L5-S1 level via the classical posterolateral approach.

Firstly, it can reduce the difficulties of acupuncture. In the conventional TESSYS technique, an 18-gauge needle is inserted toward the middle line of the vertebral canal under AP imaging and toward the vertebral posterior superior margin under lateral imaging, and subsequently, foraminoplasty is performed to achieve a sufficient level of surgical access for PTED. If needed, the targeted point can be adjusted for special extruded and sequestered disc fragments. When the high iliac crest, large L5 transverse process, and large facet joint obstruct the trajectory at the L5-S1 level, the ideal or targeted puncture point is timeconsuming, difficult, or even inaccessible to reach, and the foraminoplasty time and fluoroscopy time increase correspondingly. ZESSYS is a dual-cannula adjustment instrument with a thin cannula containing a Kirschner wire for orientation and a larger cannula for bony abrasion by a trephine (Fig. 1). Primary puncture with an 18-gauge needle was only demanded

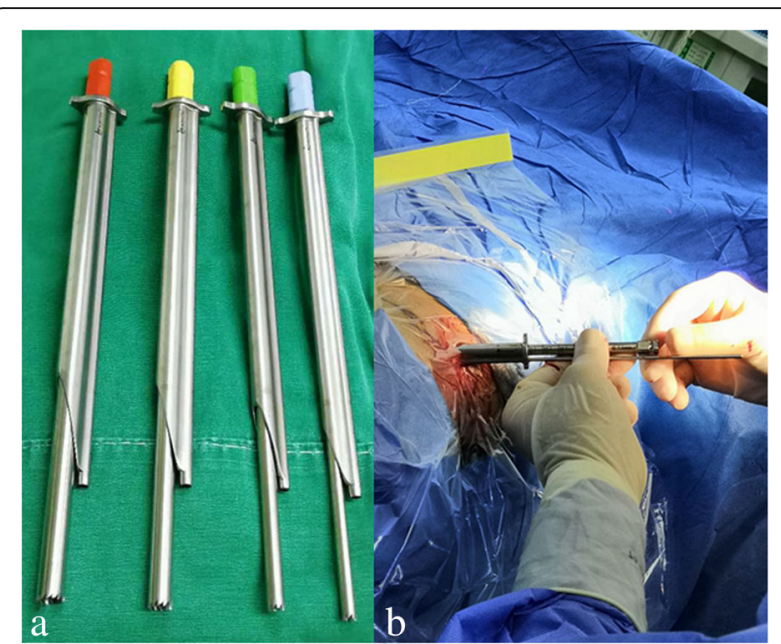

Fig. 1 Composition of the ZESSYS device: a 4 graded dual-cannula size. $\mathbf{b}$ The thinner cannula containing the Kirschner wire for fixation and the other larger cannula that was used with a trephine for foraminoplasty

to cross the safe triangle area stepwise; after the guidewire was introduced and graded dilation was performed, the traditional guidewire was replaced with a $2.5-\mathrm{mm}$ Kirschner wire and slightly hammered to fix on the posterior aspect of the distal vertebra, which could guide the following introduction of the dual-cannula device for foraminoplasty. The trajectory of the Kirschner wire did not need to strive for the accurate requirement of the TESSYS technique; it was necessary to insert the wire between the exiting nerve root and the SAP, and it could be fixed at any position near the superior-lateral part of the posterior aspect of the distal vertebra. The double-cannula system takes advantage of rotation and can be easily adjusted to find a proper and targeted entry point on the SAP, which can compensate for the Kirschner wire primary puncture point (Fig. 2). In addition, depending on the last trajectory of the Kirschner wire, size 4 of the graded dual-cannula size may be selected for selective resection of the SAP for quantificational foraminoplasty (Figs. 1 and 2). However, as a rule, an extruding or sequestrated disc fragment is within the scope of the working channel's coverage. In addition, if predetermined effective access to enter or across the safe triangle area is hard to achieve or inaccessible by using an 18-gauge needle in the case of a large L5 transverse process, large facet joint, narrowed disc space, or narrow foramen impeding the predefined trajectory, after replacement, the Kirschner wire can take place of the needle for the puncture process as it is more rigid and easier to adjust. In particular, the use of a Kirschner wire with a $2.5-\mathrm{mm}$ diameter 


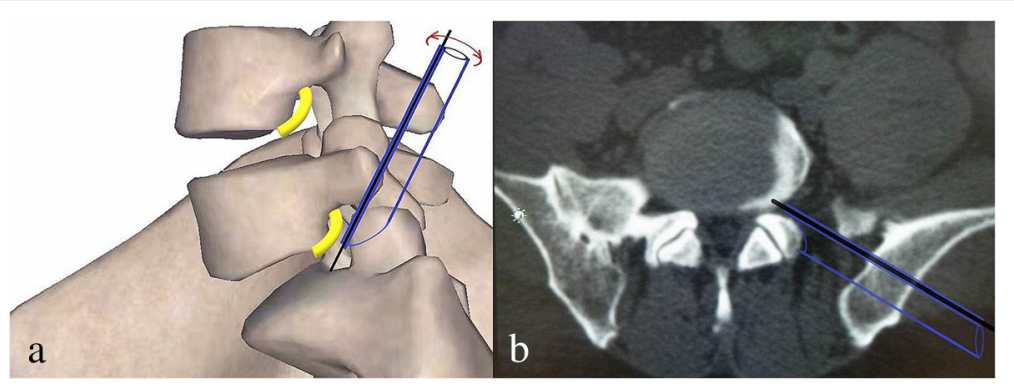

Fig. 2 Schematic diagram of the ZESSYS device: The black line segment represents the Kirschner wire, acting as a steady pivot for the doublecannula device. The purple graphics represents the double-cannula device that can be rotated with the Kirschner wire as a center to find proper foraminoplasty trajectory and achieve quantificationally decompression by selection of four different sizes

for trajectory adjustment and fixation in the safe triangle area increases the risk of nerve root damage, so when the Kirschner wire advances into the foramen, it should cling to the ventral aspect of the SAP, and the patient's responses should be taken into consideration to avoid possible nerve root and adjacent soft tissue injury. If possible, the tip of the Kirschner wire should be fixed between the inner side of the SAP and the middle line in the anteroposterior view, thereby allowing a small amount of abrasion with the upper articular process.

Secondly, the ZESSYS device can improve the efficiency and safety of foraminoplasty. As mentioned above, among the anatomical limitations at the L5-S1 level, the iliac crest is considered a major obstacle [25, 26]. When the iliac crest is located above the middle of the L5 pedicle in the lateral radiograph, foraminoplasty may be required [27]. In addition, if the working spaces

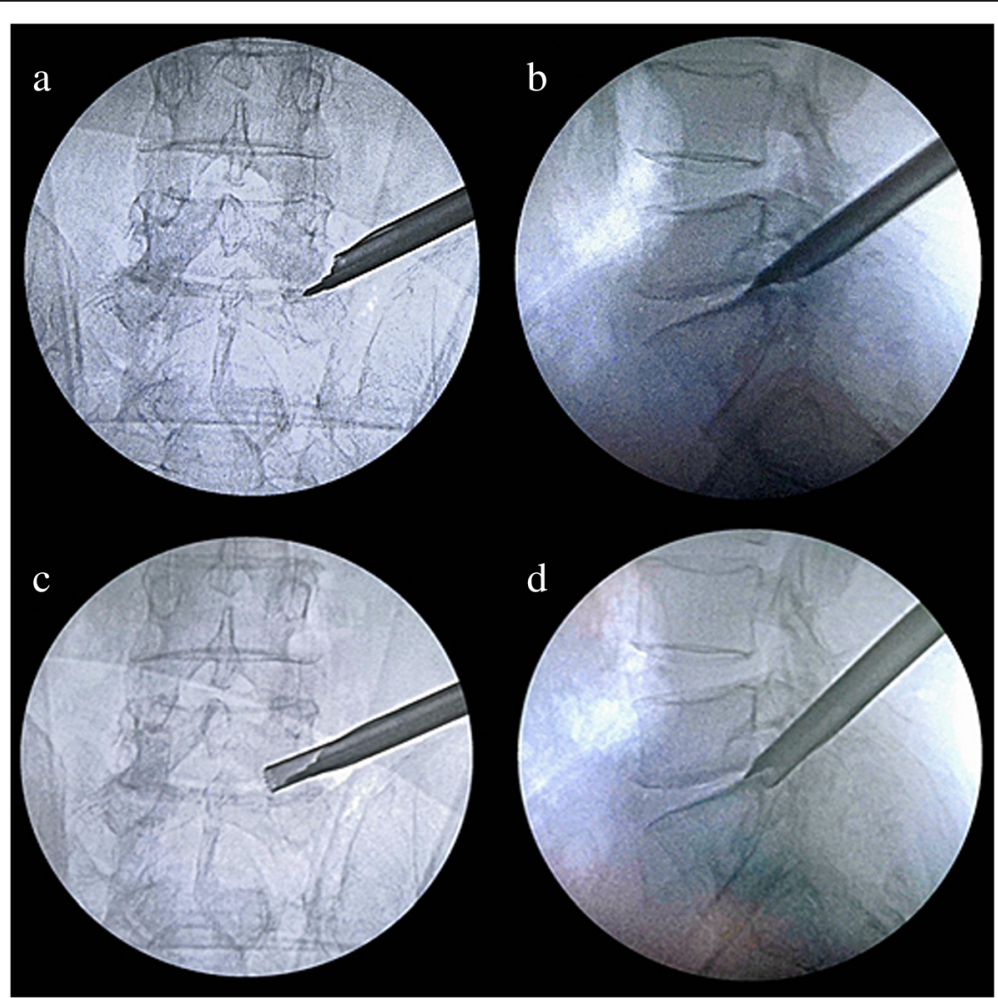

Fig. 3 The targeted and quantificational foraminoplasty process: a, b Following Kirschner wire insertion, the double-cannula device with a properly predetermined diameter was inserted and rotated for a predetermined trajectory. $\mathbf{c}$, $\mathbf{d}$ Foraminoplasty was performed by a trephine; the exiting nerve root was excluded from the working zone and the Kirschner wire acted as a steady pivot 


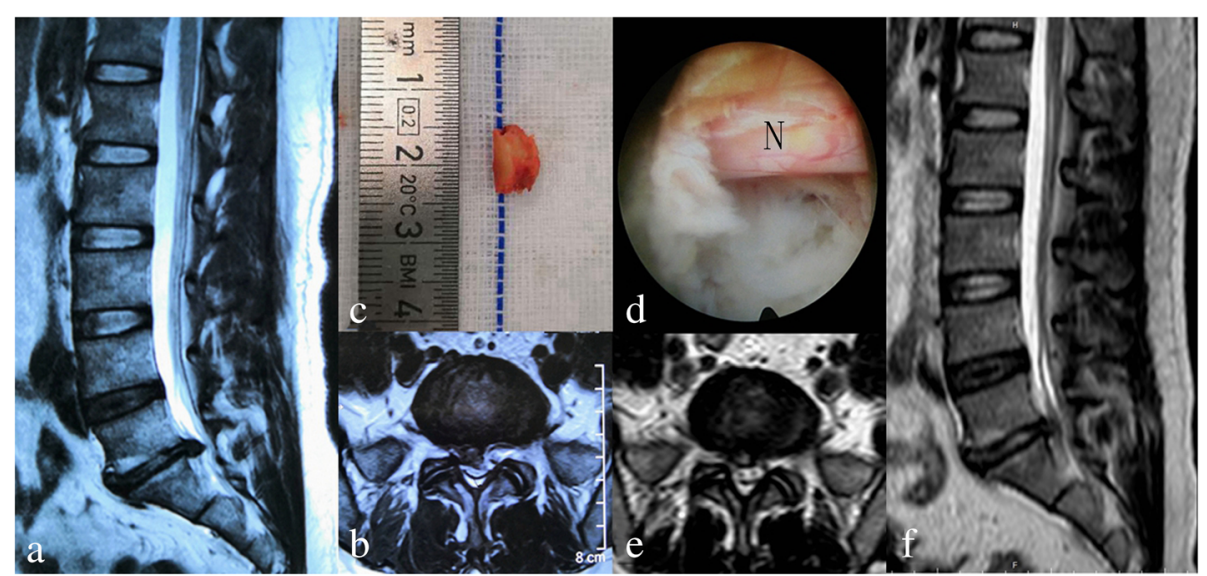

Fig. 4 One case in the ZESSYS group. a, b A 57-year-old female patient diagnosed with lumbar disc herniation at L5-S1 and underwent PTED with the ZESSYS device. $\mathbf{c}$ Part of the ventral side of the SAP was cut and removed during the foraminoplasty procedure. $\mathbf{d}$ The S1 nerve root (N) was clearly visualized. e, f Postoperative (3 days after surgery) MRI scan showing good decompression and incomplete annulus restoration

are limited by the other anatomical limitations, foraminoplasty is also necessary. In the conventional TESSYS technique, the foramen is widened gradually by an isocentric trephine. During the process of foraminoplasty, the trephine blade makes close contact with foramen soft tissue and nerve roots, leading to a risk of damage, especially for the L5-S1 level with a narrowed disc space and intervertebral foramen than the other levels. During the PTED process with ZESSYS, a 2.5-mm Kirschner wire is passed between the SAP and exiting nerve root and fixed on the posterior aspect of the distal vertebra, which acts as a steady pivot for the double-cannula device. When the predefined cannula is inserted to dock on the SAP at posterior orientation, it can be easily rotated to find the proper trajectory and achieve quantificationally decompression. In addition, the beveled design cannula is placed next to the ventral side of the SAP, excluding the exiting nerve root from the working zone of the trephine and protecting the exiting nerve root from damage. If needed, the foramen can be enlarged by a second cannula rotation. The double cannulas greatly reduce the difficulty of foraminoplasty and enable foraminoplasty to be performed more precisely (Figs. 3 and 4).

According to our study, the ZESSYS device is more efficient than the TESSYS device in the puncture and foraminoplasty procedures. The fluoroscopy time decreased with the application of ZESSYS, which was beneficial for both the patients and surgeons. The preliminary postoperative outcomes seemed to be equal between the ZESSYS group and TESSYS group. However, 1 patient in the TESSYS group experienced slight dysesthesia after surgery which was a common complication of PTED $[18,23,28]$. There were no cases of severe complications in the ZESSYS group. One of the reasons for this result might be that the new instrument not only effectively widened the foramen but also effectively protected the nerve root.

Nevertheless, our study has some limitations. Firstly, the sample sizes of the two groups were small, and the follow-up time was short. The clinical outcome was preliminary, and a larger study needs to be conducted in the future to verify the reliability of the ZESSYS system. In addition, at the L5-S1 level, the unique anatomical limitations were triaxial and complicated, and there were no specific protocols for the evaluation of the anatomical limitations. Therefore, in this study, we analyzed two major anatomical limitations between the two groups, which may not be enough and may affect the statistical correctness.

\section{Conclusion}

The double-cannula device named ZESSYS is effective and safe for PTED for L5-S1 disc herniation. It was more efficient in the puncture and foraminoplasty procedure, as well as protected the exiting nerve effectively and minimized the degree of radiation exposure.

\section{Abbreviations \\ PTED: Percutaneous transforaminal endoscopic discectomy; LDH: Lumbar disc herniation; VAS: Visual analog scale; ODI: Oswestry Disability Index; SAP: Superior articular process; POD: Postoperative dysesthesia; MRI: Magnetic resonance imaging; CT: Computed tomography; TESS YS: Transforaminal endoscopic surgical system}

\section{Acknowledgements \\ Not applicable.}

Authors' contributions

$J L$ and JW: conceptualization, methodology, data curation, and writing of the original draft. HZ: data curation and formal analysis. RZ and JL: investigation 
and data curation. CZ: conceptualization, methodology, supervision, writing review, and editing. The authors read and approved the final manuscript.

\section{Funding}

This work was supported by Chongqing Science and Health Major Project Foundation(2019ZDXM018)

\section{Availability of data and materials}

All data generated or analyzed during this study are included in the article.

\section{Declarations}

\section{Ethics approval and consent to participate}

Ethical approval was obtained by the Ethics Committee of Xinqiao Hospital at the Army Medical University. All consents to participate were obtained from the participants.

\section{Consent for publication}

We have consent for publication for every patient in our series.

\section{Competing interests}

The authors declare that they have no competing interests.

\section{Author details}

'Department of Spine Surgery, People's Hospital of Liaocheng, Liaocheng 252000, Shandong, China. ${ }^{2}$ Department of Orthopaedics, The 941th Hospital of Joint Logistics Support Force of Chinese PLA, Xining 810000, Qinghai, China. ${ }^{3}$ Department of Orthopaedics, The Hospital of People Liberation Army Hong Kong Garrison, Hong Kong 999077, China. ${ }^{4}$ Department of Spine Surgery, Xinqiao Hospital, Army Medical University, Chongqing 400037, China.

Received: 25 March 2021 Accepted: 8 June 2021

\section{Published online: 22 June 2021}

\section{References}

1. Tu Z, Li YW, Wang B, Lu G, Li L, Kuang L, et al. Clinical outcome of full-endoscopic interlaminar discectomy for single-level lumbar disc herniation: a minimum of 5-year follow-up. Pain Physician. 2017;20(3): E425-E30

2. Ahn SS, Chin DK, Kim SH, Kim DW, Lee BH, Ku MG. The clinical significance of lumbosacral transitional vertebrae on the surgical outcomes of lumbar discectomy: a retrospective cohort study of young adults. World Neurosurg. 2017:99:745-50. https://doi.org/10.1016/..wneu.2016.05.073.

3. Kim R, Kim RH, Kim CH, Choi Y, Hong HS, Park SB, et al. The incidence and risk factors for lumbar or sciatic scoliosis in lumbar disc herniation and the outcomes after percutaneous endoscopic discectomy. Pain Physician. 2015; 18(6):555-64.

4. Urrutia J, Zamora T, Prada C. The prevalence of degenerative or incidental findings in the lumbar spine of pediatric patients: a study using magnetic resonance imaging as a screening tool. Eur Spine J. 2016;25(2):596-601. https://doi.org/10.1007/s00586-015-4099-3.

5. Li X, Hu Z, Cui J, Han Y, Pan J, Yang M, et al. Percutaneous endoscopic lumbar discectomy for recurrent lumbar disc herniation. Int I Surg. 2016;27: 8-16. https://doi.org/10.1016/j.jijsu.2016.01.034.

6. Kim HS, Yudoyono F, Paudel B, Kim KJ, Jang JS, Choi JH, et al. Analysis of clinical results of three different routes of percutaneous endoscopic transforaminal lumbar discectomy for lumbar herniated disk. World Neurosurg. 2017;103:442-8. https://doi.org/10.1016/j. wneu.2017.04.008

7. Kim CH, Chung CK, Choi Y, Shin S, Kim MJ, Lee J, et al. The selection of open or percutaneous endoscopic lumbar discectomy according to an age cut-off point: nationwide cohort study. Spine (Phila Pa 1976). 2015;40(19): E1063-70. https://doi.org/10.1097/BRS.0000000000001053.

8. Zhang B, Liu S, Liu J, Yu B, Guo W, Li Y, et al. Transforaminal endoscopic discectomy versus conventional microdiscectomy for lumbar discherniation: a systematic review and meta-analysis. J Orthop Surg Res. 2018;13(1):169 https://doi.org/10.1186/s13018-018-0868-0

9. Pan Z, Ha Y, Yi S, Cao K. Efficacy of transforaminal endoscopic spine system (TESSYS) technique in treating lumbar disc herniation. Med Sci Monit. 2016; 22:530-9. https://doi.org/10.12659/MSM.894870.
10. Hoogland T, Schubert M, Miklitz B, Ramirez A. Transforaminal posterolateral endoscopic discectomy with or without the combination of a low-dose chymopapain: a prospective randomized study in 280 consecutive cases. Spine (Phila Pa 1976). 2006;31(24):E890-7. https://doi.org/10.1097/01.brs. 0000245955.22358 .3 .

11. Choi G, Lee SH, Lokhande P, Kong BJ, Shim CS, Jung B, et al. Percutaneous endoscopic approach for highly migrated intracanal disc herniations by foraminoplastic technique using rigid working channel endoscope. Spine (Phila Pa 1976). 2008;33(15):E508-15. https://doi.org/10.1097/BRS.0b013e31 $817 \mathrm{bfa} 1 \mathrm{a}$.

12. Kubaszewski L, Kaczmarczyk J, Nowakowski A, Sulewski A. Foraminoplastic transfacet epidural endoscopic approach for removal of intraforaminal disc herniation at the L5-S1 level. Wideochir Inne Tech Maloinwazyjne. 2014;9(1): 96-100. https://doi.org/10.5114/wiitm.2014.40186.

13. Lee SH, Kang HS, Choi G, Kong BJ, Ahn Y, Kim JS, et al. Foraminoplastic ventral epidural approach for removal of extruded herniated fragment at the L5-S1 level. Neurol Med Chir (Tokyo). 2010;50(12):1074-8. https://doi. org/10.2176/nmc.50.1074.

14. Ao S, Wu J, Zheng W, Zhou Y. A novel targeted foraminoplasty device improves the efficacy and safety of foraminoplasty in percutaneous endoscopic lumbar discectomy: preliminary clinical application of 70 cases. World Neurosurg. 2018;115:e263-e71. https://doi.org/10.1016/j.wneu.2018. 04.032 .

15. Lee S, Lee JW, Yeom JS, Kim KJ, Kim HJ, Chung SK, et al. A practical MRI grading system for lumbar foraminal stenosis. AJR Am J Roentgenol. 2010; 194(4):1095-8. https://doi.org/10.2214/AJR.09.2772.

16. Choi KC, Park CK. Percutaneous endoscopic lumbar discectomy for L5-S1 disc herniation: consideration of the relation between the iliac crest and L5S1 disc. Pain Physician. 2016;19(2):E301-8. https://doi.org/10.36076/ppj/201 6.19.E301.

17. Schubert M, Hoogland T. Endoscopic transforaminal nucleotomy with foraminoplasty for lumbar disk herniation. Oper Orthop Traumatol. 2005; 17(6):641-61. https://doi.org/10.1007/s00064-005-1156-9.

18. Zhou YL, Chen G, Bi DC, Chen X. Short-term clinical efficacy of percutaneous transforaminal endoscopic discectomy in treating young patients with lumbar disc herniation. J Orthop Surg Res. 2018;13(1):61. https://doi.org/10.1186/s13018-018-0759-4.

19. Cho JY, Lee SH, Lee HY. Prevention of development of postoperative dysesthesia in transforaminal percutaneous endoscopic lumbar discectomy for intracanalicular lumbar disc herniation: floating retraction technique. Minim Invasive Neurosurg. 2011;54(5-6):214-8. https://doi.org/10.1055/s0031-1287774

20. Shi C, Kong W, Liao W, Lu Y, Fu Y, Wen H, et al. The early clinical outcomes of a percutaneous full-endoscopic interlaminar approach via a surrounding nerve root discectomy operative route for the treatment of ventral-type lumbar disc herniation. Biomed Res Int. 2018;2018:9157089.

21. Fan G, Guan X, Zhang H, Wu X, Gu X, Gu G, et al. Significant improvement of puncture accuracy and fluoroscopy reduction in percutaneous transforaminal endoscopic discectomy with novel lumbar location system: preliminary report of prospective HELLO study. Medicine (Baltimore). 2015;94(49):e2189. https://doi.org/10.1097/MD. 0000000000002189

22. Wu XB, Fan GX, Gu X, Shen TG, Guan XF, Hu AN, et al. Learning curves of percutaneous endoscopic lumbar discectomy in transforaminal approach at the L4/5 and L5/S1 levels: a comparative study. J Zhejiang Univ Sci B. 2016; 17(7):553-60. https://doi.org/10.1631/jzus.B1600002.

23. Yeung AT, Tsou PM. Posterolateral endoscopic excision for lumbar disc herniation: surgical technique, outcome, and complications in 307 consecutive cases. Spine (Phila Pa 1976). 2002;27(7):722-31. https://doi.org/1 0.1097/00007632-200204010-00009.

24. Li Z, Hou S, Shang W, Song K, Zhao H. New instrument for percutaneous posterolateral lumbar foraminoplasty: case series of 134 with instrument design, surgical technique and outcomes. Int J Clin Exp Med. 2015;8(9): $14672-9$.

25. Lee JS, Kim HS, Jang JS, Jang IT. Structural preservation percutaneous endoscopic lumbar interlaminar discectomy for L5-S1 herniated nucleus pulposus. Biomed Res Int. 2016;2016:6250247.

26. Bai J, Zhang W, Wang Y, An J, Zhang J, Sun Y, et al. Application of transiliac approach to intervertebral endoscopic discectomy in L5/S1 intervertebral disc herniation. Eur J Med Res. 2017;22(1):14. https://doi.org/10.1186/s40001017-0254-0. 
27. Yang JS. Re: Choi KC, Park CK. Percutaneous endoscopic lumbar discectomy for L5-S1 disc herniation: consideration of the relation between the iliac crest and L5-S1 disc. Pain Physician. 2019;22(3):E241-E4.

28. Choi I, Ahn JO, So WS, Lee SJ, Choi IJ, Kim H. Exiting root injury in transforaminal endoscopic discectomy: preoperative image considerations for safety. Eur Spine J. 2013;22(11):2481-7. https://doi.org/10.1007/s00586013-2849-7.

\section{Publisher's Note}

Springer Nature remains neutral with regard to jurisdictional claims in published maps and institutional affiliations.

Ready to submit your research? Choose BMC and benefit from:

- fast, convenient online submission

- thorough peer review by experienced researchers in your field

- rapid publication on acceptance

- support for research data, including large and complex data types

- gold Open Access which fosters wider collaboration and increased citations

- maximum visibility for your research: over $100 \mathrm{M}$ website views per year

At BMC, research is always in progress.

Learn more biomedcentral.com/submissions 